\title{
Quality Improvement in Central Sterile Supply Department: Educational Interventions
}

\author{
Amel Ahmed ${ }^{1}$, Tahany El-Senousy ${ }^{2}$, Nemattalla Gomaa ${ }^{3}$ \\ Asmaa Abdel Rahman ${ }^{4}$ \\ ${ }^{1,2,3,4}$ Medical Surgical Nursing department, Faculty of Nursing, Ain Shams University
}

\begin{abstract}
Central sterile supply department (CSSD) is in charge of the supply of sterile medical instruments for all departments, which is a key department of preventing hospital-associated infection. It is important to assess the work quality of CSSD personnel to ensure implementation of accurate and appropriate sterilization technique. The aim of this study is to evaluate the effect of the educational interventions regarding sterilization process on quality of work delivered at the central sterile supply department. A quasi-experimental research design was utilized to meet the aim of this study. This study was conducted in the central sterile supply department in El-demerdash Hospital, affiliated to Ain Shams University hospital. A convenience sample includes all available staff (30) in the CSSD, plus 12 nursing supervisors were included in the study. Data were collected through 6 tools: (1) A self-administered nurses/technicians' knowledge assessment questionnaire. (2) Nurses' practices observational checklist. (3) Technicians' practices observational checklist. (4) A selfadministered workers' awareness assessment questionnaire. (5) Workers' practices observational checklist. (6) Structured nursing supervisors' opinionnaire. It was concluded that implementation of the educational interventions has positive effect on improving the knowledge and practice of the CSSD staff, as well as improving the satisfaction of nursing supervisors regarding the quality of work delivered by the CSSD. It is recommended to conduct periodic educational interventions for CSSD staff to improve and keep them with updated knowledge and practices regarding to medical and surgical equipment sterilization.
\end{abstract}

Keywords: CSSD, Educational intervention, Quality improvement.

\section{Introduction}

The central sterile services department (CSSD), also called sterile processing department (SPD), sterile processing, central supply department (CSD), or central supply, is an integrated place in hospitals and other health care facilities that performs sterilization and other actions on medical devices, equipment and consumables; for subsequent use by health care providers in the operating theatre of the hospital and also for other aseptic procedures, e.g. catheterization, wound stitching and bandaging in a medical, surgical, maternity or pediatric wards [1]. Ideally, CSSD is an independent department with facilities to receive, clean, pack, disinfect, sterilizes, store and distribute instruments as per well-delineated protocols [2].

A World Health Organization (WHO) survey showed an average of $8.7 \%$ of hospital patients had healthcare associated infections. At any time, over 1.4 million people worldwide suffer from infectious complications acquired in hospital [3]. The most commonly occurring healthcare acquired infections were pneumonia and lower respiratory tract infections, surgical site infections, urinary tract infections and bloodstream infections [4]. There are many worldwide reports about infection risks related to inappropriate sterilization [5].

The central sterile services department personnel should perform most cleaning, disinfecting, and sterilizing of patient-care supplies in a central processing department in order to more easily control quality. The aim of central processing is the orderly processing of medical and surgical instruments to protect patients from infections while minimizing risks to staff and preserving the value of the items are being reprocessed [6].

In order to prevent inadequate sterilization process and to improve the quality of sterilization, many efforts have been engaged into the improvement and development of sterilization process [5]. One of these efforts is equipping the central supply personnel with knowledge and experience that ensure patient safety and thus will prevent health care associate infections [7].

The international standardization organization (ISO) defines the quality improvement as the systematic and continuous actions taken throughout the organization to increase the effectiveness of activities and processes to provide added benefits to both the organization and its customers $[8,9]$.

To make improvements and ensure consistency of sterilization practices, this requires comprehensive educational interventions that ensure operator competence and proper methods of cleaning and wrapping instruments, loading the sterilizer, operating the sterilizer, and monitoring of the entire process [10]. Because of the increased incidences of surgical site infections and health care-associated infections, it is imperative that all 
steps of the sterilization process be assessed and followed consistently and conscientiously to deliver safe products for patients. Professionals should review and audit current practices and implement a workable, continuous, quality-improvement educational interventions [11].

\subsection{Significance of the study:}

There has been an increase in many infectious diseases such as acquired immunodeficiency syndrome, hepatitis $\mathrm{B}$ and $\mathrm{C}$ that have been known to be transmitted through contaminated surgical instruments. The central sterile supply department staff is valuable members of health care team assumes an important role in patient care by preventing infections through decontaminating, cleaning, processing, assembling, sterilizing, storing and distributing the medical devices and supplies needed in patient care. It is essential for the central sterile supply department staff to have adequate knowledge and practice of sterilization techniques in order to safe patient's life and decrease the incidence of nosocomial infections. Therefore, the aim of this study is to evaluate the effect of the educational interventions regarding sterilization process on quality of work delivered at the central sterile supply department.

\subsection{Aim of the study:}

This study aims to evaluate the effect of the educational interventions regarding sterilization process on quality of work delivered at the central sterile supply department through the following:

1. Assessment of the central sterile supply department staff (nurses, technicians and workers) knowledge and practices regarding to the standards sterilization process.

2. Developing and implementing tailored educational interventions based on the staff needs assessment.

3. Evaluating the effect of educational interventions regarding sterilization process on the quality of work delivered at the central sterile supply department.

\subsection{Research hypothesis:}

1. This study hypothesized that: Implementation of the educational interventions will affect the knowledge of the central sterile supply department staff positively.

2. This study hypothesized that: Implementation of the educational interventions will affect the practices of the central sterile supply department staff positively.

3. This study hypothesized that: Implementation of the educational interventions will affect the satisfaction of nursing supervisors regarding the quality of work delivered by the central sterile supply department staff positively.

\subsection{Research design:}

\section{Methods}

A quasi-experimental research design (one group pre-test, post-test design) was utilized to meet the aim of this study. It studies the effect of educational interventions on the same group through comparing pre and post assessment results.

\subsection{Setting:}

This study was conducted in the central sterile supply department, located in the $1^{\text {st }}$ floor at El-Demerdash Hospital, affiliated to Ain Shams University hospital, Cairo, Egypt.

\subsection{Subjects:}

A convenience sample includes all available staff (12 nurses, 10 technicians and 8 workers) who is working in the central sterile supply department at El-demerdash hospital. Also the subjects includes all available nursing supervisors (12 head nurses) who are working in the operating theater and general surgery wards at Eldemerdash Hospital affiliated to Ain Shams University.

\subsection{Tools for data collection:}

Six tools for data collection were used as follow:

\subsubsection{A self-administered nurses/technicians' knowledge assessment questionnaire regarding sterilization process:}

This questionnaire was developed by the researcher in an Arabic language based on the updated related literatures [12] to assess nurses/technicians' knowledge regarding the six keys components of surgical and medical equipment sterilization. It includes two parts as follow:

- First part was concerned with the demographic characteristics of the central sterile supply department nurses/technicians such as age, gender, qualifications, years of experience and previous training courses.

- Second part was concerned with the assessment of nurses/technicians' knowledge regarding the six keys components of surgical and medical equipment sterilization that includes cleaning, packaging, disinfection and sterilization of surgical equipment and instruments, storage and transferring of sterile supplies. It included 81 
statements which were grouped into 6 subgroups; cleaning (24 items), packaging (9 items), disinfection (9 items), and sterilization of equipment (30 items), storage (6 items), and transferring of sterile supplies ( 3 items).

\section{Scoring system}

- This part is consisted of 81 statements; the responses for the statements were either by true or false for 28 items or by choosing the correct answer for 53 MCQ.

- The correct answer was given (1 grade).

- The incorrect answer was given (zero).

- The total grade was (81 grades).

- The total scores for every subgroup were calculated, and then the total score for the entire questionnaire was calculated for every nurse/technician. Then the mean of the total score for all nurses/technicians was calculated.

\subsubsection{Nurses' practices observational checklist:}

This checklist was used to assess nurses' practices for their responsibilities regarding sterilization of surgical and medical equipments. It included 63 statements which were grouped into 6 subgroups; manual cleaning of equipment immersion method (16 items), assembling cleaned items for sterilization (19 items), manual cleaning method (9 items), mechanical cleaning (9 items), lubrication of instruments for sterilization (3 items), and use glutaraldehyde as disinfection (7 items). It was adopted from the Standard of Australia, 2014. AS/NZS 4187:2014 [13].

\section{Scoring system}

- The responses for the 63 statements were either by done correctly or done incorrectly.

- One grade was given for each correct step and zero for each incorrect step.

- The total scores for the observation checklist were (63 grades).

- The total score of the checklist was calculated for every nurse. Then the mean of the total score for all nurses was calculated.

\subsubsection{Technicians' practices observational checklist:}

This checklist was used to assess technicians' practices for their responsibilities regarding sterilization of surgical and medical equipments. It included 76 statements which were grouped into 4 subgroups; preparation of instruments, sets, packs, and supplies for sterilization (41 items), loading sterilizer for sterilization (10 items), unloading sterilizer for sterilization (18 items), cleaning of ultrasonic cleaner (7 items). It was adopted from the Standard of Australia, 2014. AS/NZS 4187:2014 [13].

\section{Scoring system}

- The responses for the 76 statements were either by done correctly or done incorrectly.

- One grade was given for each correct step and zero for each incorrect step.

- The total scores for the observation checklist were (76 grades).

- The total score of the checklist was calculated for every technician. Then the mean of the total score for all technicians was calculated.

\subsubsection{A self-administered workers' awareness assessment questionnaire regarding sterilization process:}

This questionnaire was developed by the researcher in an Arabic language based on the updated related literatures to assess workers' awareness regarding the six keys components of surgical and medical equipment sterilization. It includes two parts:

- First part was concerned with the demographic characteristics of the central sterile supply department workers such as age, gender, qualifications, years of experience and previous training session.

- Second part was concerned with the assessment of workers' awareness of their roles within the team work regarding the six keys components of surgical and medical equipment sterilization. It included 63 statements which were grouped into 6 subgroups; cleaning (17 items), packaging ( 9 items), and disinfection of equipment ( 9 items), sterilization of equipment (18 items), storage ( 7 items), and transferring of sterile supplies ( 3 items).

\section{Scoring system}

- The responses for the 63 statements were either by true or false for 27 items or by choosing the correct answer for $36 \mathrm{MCQ}$.

- The correct answer was given (1 grade).

- The incorrect answer was given (zero).

- The total grade was (63 grades).

- The total score for every subgroup were calculated by summing the workers' responses, and then the total score for the entire questionnaire was calculated for every worker. Then the mean of the total score for all workers was calculated. 


\subsubsection{Workers' practices observational checklist:}

This checklist was developed by the researcher in an Arabic language based on the related literatures (Young, 2014) [14] to assess workers' practices for their responsibilities regarding ground, surfaces and environmental cleaning of central sterile supply department. It included 20 statements based on the workers duties and job description.

Scoring system

- The response for the 20 statements were either by done correctly or done incorrectly.

- One grade was given for each correct step and zero for each incorrect step.

- The total scores for the observation checklist were (20 grades).

- The total score of the checklist was calculated for every worker. Then the mean of the total score for all workers was calculated.

\subsubsection{Structured nursing Supervisors' opinionaire:}

This tool was developed by the researcher in an Arabic language and guided by (Shriyan \& Shriyan, 2015; Kooshkebaghi, Ravaghi \& Khalesi, 2015) $[15,16]$ to assess nursing supervisors' opinion regarding the services that was provided by the central sterile supply department pre and post implementation of the educational interventions as an indicator for the improvement of quality of work at the central sterile supply department. It included 13 statements.

\section{Scoring system}

- The responses for the 13 statements were either by yes or no.

- The total scores for the observation checklist were (13 grades).

- The total score of the questionnaire was calculated for every nursing supervisor. Then the mean of the total score for all nursing supervisors was calculated.

Operational definition: Quality improvement state is the actions taken throughout the organization to increase the effectiveness of activities and processes to provide added benefits to both the organization and its customers. Or it is a formal approach to the analysis of performance and systematic efforts for improvement [9]. In this study the improvement in quality was assessed by nursing supervisors' opinion regarding the services that was provided by the central sterile supply department pre and post implementation of the educational instructions as an indicator for the improvement of quality of work at the central sterile supply department.

\subsection{Tool validity and reliability:}

- The tools were evaluated in terms of face and content validity by a panel of 7 experts in medical surgical nursing department, Ain shams university (4 professors, 2 assistant professors and one lecturer). The experts reviewed the tools for its content, clarity, simplicity, relevance, comprehensiveness, appropriateness and applicability. Minor modifications were done and then the final forms of tools were developed.

- Testing the reliability of the purposed data collecting tools were done by alpha cronbach test that was 0.845 for self administered questionnaire and 0.952 for observation checklist for the central sterile supply department staff.

\subsection{Pilot study:}

A pilot study was carried out on $10 \%$ of the studied subject to test the applicability and clarity of the designed tools, as well as to estimate the time needed to fill in each study tool. The modifications were done for the used tools then the final form was developed. Study subjects of the pilot study were excluded from the study's subjects and replaced by another staff.

\subsection{Ethical considerations:}

The research approval was obtained from the research ethical committee of faculty of nursing before initiating the study. The researcher clarified the objectives and aim of the study to the study subjects included in the study. Oral consent was obtained from the study subjects to ensure willingness to participate in the study. The researcher assured maintaining anonymity and confidentiality of subjects' data. The study subjects were informed that they are allowed to withdraw from the study at any time without penalty.

\subsection{Procedure:}

Procedure included three phases: preparatory phase, implementation phase and evaluation phase.

\subsubsection{Preparatory phase:}

- This phase involved extensive reviewing of the recent related literatures to develop tools for data collection.

- The researcher interviewing the study subjects to explain the aim and purpose of the study as well as taking the approval of the study subjects to participate in this study prior to data collection.

DOI: 10.9790/1959-0602090616 $\quad$ www.iosrjournals.org 9 Page


- The study subjects (nurses, technicians, workers) fill in the self administered knowledge assessment questionnaire in the presence of the researcher. It took 30-45 minutes to fill in these questionnaires.

- The nursing supervisors fill in their opinionaire tool. It took 10 minutes to complete it.

- The observation checklists for nurses, technicians and workers were filled in by the researcher before implementation of the educational interventions. It took 30-45 minutes to fill in these questionnaires.

- The collected data were interpreted for identifying CSSD's staff training needs.

- The researchers developed educational interventions booklet about surgical and medical equipments sterilization in an Arabic language based on identifying needs including terminologies, cleaning types and procedures, disinfection levels and procedures, sterilization methods and procedures, packaging procedures, storage of sterilized equipments and environmental cleaning.

\subsubsection{Implementation phase:}

- The teaching sessions were conducted at the training room in the central sterilization supply department.

- At the beginning of the each session, the researcher gets feedback about the previous session and shows the objectives of the new one.

- The educational interventions were introduced to the CSSD's staff in 12 sessions (4 sessions for theory and 8 for practices). Every session continue for 45 minutes. The first session about cleaning of surgical and medical equipments. The second one included procedure of manual cleaning, assembling and arrangement of cleaned items. The third session related to mechanical cleaning methods and clean ultrasonic cleaner procedure. The fourth session regarding lubrication of surgical and medical equipments procedure. The fifth one was about disinfection process of surgical and medical equipments. The sixth session concerned with disinfection procedure of surgical and medical equipments. The seventh one regarding package of instruments. The eighth session related to procedure of preparing instruments, sets, and packs for sterilization. The ninth about sterilization methods for surgical instruments. The tenth session regarding procedure of loading and unloading sterilizer of surgical instruments. The eleventh one about storage and transferring of sterile surgical and medical equipments. The twelfth session concerned with environmental cleaning for workers.

- The collection of data and application of educational interventions lasted over a period of seven months; starting at April 2016 and ending in October 2016 during the morning shift, four days per week.

- The booklet was distributed to the study subjects and informed that they will be reevaluated after implementing educational interventions.

\subsubsection{Evaluation phase:}

After implementation of the educational interventions, all tools were filled in again immediately. Evaluation of the effect of educational interventions was done by comparing the results of CSSD staff (nurses, technicians and workers) knowledge and practice pre and post the implementation and comparing nursing supervisors' opinions pre and posts the implementation by using the same data collection tools.

\subsection{Data analysis:}

The data were collected, coded and entered into a suitable excel sheet. Data were analyzed using SPSS version 18 for analysis. Quantitative data were presented as mean and standard deviation; comparison was done using paired $t$ test. Qualitative data were presented as percentages. The observed differences was considered as significant at $\mathrm{P}<0.05$

\section{Results}

The demographic data of the studied subjects were shown in table 1 . The current study revealed that the mean age of nurses under study was $42.6 \pm 5.78$ and all (100\%) of them were females. The mean years of experiences for them was $11.52 \pm 2.3$ and more than half $(58.3 \%)$ of them attended training courses about medical and surgical equipment sterilization process. Regarding the mean age of technicians under study, it was $43.12 \pm 6.71$ and all of them $(100 \%)$ were males. The mean years of experience for technicians were $12.49 \pm 1.89$ and half $(50 \%)$ of them attended training courses about medical and surgical equipment sterilization process. The present study shows that the mean age of workers was $41.37 \pm 3.16$ and about third of them $(30 \%)$ were males. The mean years of experience for workers was $9.65 \pm 2.27$ and all of them (100\%) attended previous training courses about medical and surgical equipment sterilization process.

Table 1: Demographic characteristics of the studied subjects $(\mathrm{n}=30)$

\begin{tabular}{|c|c|c|c|c|c|c|c|c|}
\hline \multirow[t]{2}{*}{ Items } & \multicolumn{2}{|c|}{$\begin{array}{c}\text { Nurses } \\
\mathrm{N}=12\end{array}$} & \multicolumn{2}{|c|}{$\begin{array}{c}\text { Technician } \\
\mathrm{N}=10\end{array}$} & \multicolumn{2}{|c|}{$\begin{array}{c}\text { Workers } \\
\mathrm{N}=8\end{array}$} & \multicolumn{2}{|c|}{$\begin{array}{l}\text { Total } \\
\mathrm{N}=30\end{array}$} \\
\hline & No & $\%$ & No & $\%$ & No & $\%$ & No & $\%$ \\
\hline Gender & & & & & & & & \\
\hline Females & 12 & 100 & - & - & 5 & 70 & 17 & 56 \\
\hline
\end{tabular}


Quality Improvement in Central Sterile Supply Department: Educational Interventions

\begin{tabular}{|c|c|c|c|c|c|c|c|c|}
\hline Males & - & - & 10 & 100 & 3 & 30 & 13 & 44 \\
\hline \multicolumn{9}{|l|}{ Age } \\
\hline$<30$ year & 3 & 25.0 & 2 & 20 & - & - & 5 & 16.6 \\
\hline $30<50$ year & 7 & 58.3 & 6 & 60 & 8 & 100 & 21 & 70 \\
\hline$\geq 50$ year & 2 & 16.7 & 2 & 20 & - & - & 4 & 13.4 \\
\hline Mean \pm SD & \multicolumn{2}{|c|}{$\frac{1}{42.6 \pm 5.78}$} & \multicolumn{2}{|c|}{$\frac{1}{43.12 \pm 6.71}$} & \multicolumn{2}{|c|}{$41.37 \pm 3.16$} & \multicolumn{2}{|c|}{$\frac{1}{42.36 \pm 5.22}$} \\
\hline \multicolumn{9}{|l|}{ Educational level } \\
\hline Diploma, Technical institute & 10 & 83.3 & 10 & 100 & 8 & 100 & 28 & 93.3 \\
\hline Others & 2 & 16.7 & - & - & - & - & 2 & 6.7 \\
\hline \multicolumn{9}{|l|}{ Years of experiences } \\
\hline$<5$ years & 5 & 41.7 & 5 & 50 & - & - & 10 & 33.4 \\
\hline $10 \leq 20$ year & 3 & 25.0 & 2 & 20 & 7 & 87.5 & 12 & 40 \\
\hline$\geq 20$ year & 4 & 33.3 & 3 & 30 & 1 & 12.5 & 8 & 26.6 \\
\hline Mean \pm SD & \multicolumn{2}{|c|}{$11.52 \pm 2.3$} & \multicolumn{2}{|c|}{$12.49 \pm 1.89$} & \multicolumn{2}{|c|}{$9.65 \pm 2.27$} & \multicolumn{2}{|c|}{$11.22 \pm 2.15$} \\
\hline \multicolumn{9}{|c|}{ Previous training courses attended } \\
\hline Yes & 7 & 58.3 & 5 & 50 & 8 & 100 & 20 & 66.6 \\
\hline No & 5 & 41.7 & 5 & 50 & - & - & 10 & 33.4 \\
\hline \multicolumn{9}{|c|}{ Number of training courses attended } \\
\hline One & 4 & 57.1 & 2 & 33.3 & 3 & 37.5 & 9 & 30 \\
\hline Two & 2 & 28.6 & 2 & 33.3 & 2 & 25 & 6 & 20 \\
\hline Three & - & - & - & - & 3 & 37.5 & 3 & 10 \\
\hline Six & 1 & 14.3 & - & - & - & - & 1 & 3.3 \\
\hline Ten & - & - & 1 & 33.3 & - & - & 1 & 3.3 \\
\hline
\end{tabular}

In relation to the differences between mean scores of nurses' knowledge related to six components of equipment sterilization pre and post implementation of educational interventions, Table 2 reveals the highly statistically significant differences between mean scores of the pre and post test regarding equipment cleaning, disinfection, sterilization and storage, and statistically significant differences between mean scores of the pre and post test regarding equipment packaging and transferring. In addition, there was highly statistically significant difference between the mean scores of the total knowledge pre and post implementation of educational interventions.

Table 2: Differences between mean scores of nurses' knowledge regarding six components of equipment sterilization pre and post implementation of educational interventions $(\mathrm{n}=12)$

\begin{tabular}{|l|c|c|c|c|}
\hline $\begin{array}{l}\text { Six components of } \\
\text { equipment } \\
\text { sterilization }\end{array}$ & Pre & Post & \multicolumn{2}{|c|}{ Paired t-test } \\
\cline { 3 - 5 } & & & \multicolumn{2}{|c|}{ Pre \& post } \\
\cline { 2 - 5 } Cleaning & Mean \pm SD & Mean \pm SD & T & P-value \\
\hline Packaging & $11.57 \pm 2.81$ & $20.47 \pm 2.34$ & 8.431 & $0.001^{* *}$ \\
\hline Disinfection & $6.23 \pm 1.26$ & $7.62 \pm 1.15$ & 2.823 & $0.009^{*}$ \\
\hline Sterilization & $3.14 \pm 1.15$ & $7.89 \pm 0.95$ & 11.031 & $0.001^{* *}$ \\
\hline Storage & $12.42 \pm 2.37$ & $26.39 \pm 1.43$ & 17.483 & $0.001^{* *}$ \\
\hline Transferring & $3.57 \pm 1.12$ & $5.24 \pm 0.62$ & 4.519 & $0.001^{* *}$ \\
\hline Total knowledge & $1.58 \pm 0.84$ & $2.55 \pm 0.44$ & 3.544 & $0.002^{*}$ \\
\hline Significant $<\mathbf{0 . 0 5 *}$ & \multicolumn{2}{|c|}{ highly significant $\leq \mathbf{0 . 0 0 1 * *}$} & 11.956 & $0.001^{* *}$ \\
\hline
\end{tabular}

In relation to the differences between mean scores of technicians' knowledge related to six components of equipment sterilization pre and post implementation of educational interventions, Table 3 shows the highly statistically significant differences between mean scores of technicians' knowledge regarding equipment cleaning, disinfection and sterilization pre and post implementation of educational interventions, as well as there was statistically significant difference between mean scores of technicians' knowledge regarding equipment packaging, storage and transferring. In addition, there is statistically significant difference between mean scores of technicians' total knowledge pre and post implementation of educational interventions.

Table 3: Differences between mean scores of technicians' knowledge regarding six components of equipment sterilization pre and post implementation of educational interventions $(\mathrm{n}=10)$

\begin{tabular}{|l|c|c|c|c|}
\hline \multirow{2}{*}{$\begin{array}{l}\text { Six components } \\
\text { of equipment } \\
\text { sterilization }\end{array}$} & Pre & \multirow{2}{*}{ Post } & \multicolumn{2}{|c|}{ Paired t-test } \\
\cline { 4 - 5 } & & & \multicolumn{2}{|c|}{ Pre \& post } \\
\hline Cleaning & Mean \pm SD & Mean \pm SD & T & P-value \\
\hline Packaging & $10.83 \pm 2.64$ & $19.84 \pm 2.34$ & 8.077 & $0.001^{* *}$ \\
\hline Disinfection & $5.98 \pm 1.05$ & $7.34 \pm 1.15$ & 2.762 & $0.013^{*}$ \\
\hline Sterilization & $2.97 \pm 1.27$ & $7.56 \pm 0.95$ & 9.152 & $0.001^{* *}$ \\
\hline Storage & $12.57 \pm 2.09$ & $24.77 \pm 1.43$ & 15.235 & $0.001^{* *}$ \\
\hline
\end{tabular}




\begin{tabular}{|l|c|c|c|c|}
\hline Transferring & $1.62 \pm 0.90$ & $2.45 \pm 0.54$ & 2.501 & $0.022^{*}$ \\
\hline Total knowledge & $41.50 \pm 13.39$ & $66.40 \pm 7.43$ & 3.970 & $0.003^{*}$ \\
\hline
\end{tabular}

Concerning the difference between mean scores of workers' total awareness related to six components of equipment sterilization pre and post implementation of educational interventions, Table 4 shows that, there is highly statistically significant difference between mean score of workers' total pre and post implementation of the educational interventions.

Table 4: Differences between mean scores of workers' total awareness related to six components of equipment sterilization pre and post implementation of educational interventions $(\mathrm{n}=8)$

\begin{tabular}{|c|c|c|c|}
\hline \multirow{2}{*}{$\begin{array}{c}\text { Stages of } \\
\text { assessment }\end{array}$} & \multicolumn{3}{|c|}{ Workers' total knowledge } \\
\cline { 2 - 4 } & Mean \pm SD & t & P-value \\
\hline Pre & $33.38 \pm 2.00$ & \multirow{2}{*}{11.444} & $0.001 * *$ \\
\hline Post & $46.25 \pm 1.58$ & & \\
\hline
\end{tabular}

Highly significant $\leq 0.001 * *$

As regard to the differences between mean scores of nurses' practices related to equipment sterilization pre and post implementation of educational interventions, Table 5 represents that, there was highly statistically significant differences between mean scores of pre and post tests as regards to cleaning of instruments immersion method, assemble cleaned items for sterilization, manual cleaning method, mechanical cleaning and glutaraldehyde disinfection. Also there was highly statistically significant difference between mean scores of total nurses' practices regarding equipment sterilization pre and post implementations of educational interventions.

Table 5: Differences between mean scores of nurses' practices related to equipment sterilization pre and post implementation of educational interventions $(n=12)$

\begin{tabular}{|l|c|c|c|c|}
\hline \multirow{2}{*}{$\begin{array}{l}\text { Equipment sterilization process } \\
\text { based on nurses' responsibilities }\end{array}$} & \multirow{2}{*}{ Pre } & \multirow{2}{*}{ Post } & \multicolumn{2}{c|}{ Paired t-test } \\
\cline { 3 - 5 } & & & \multicolumn{2}{|c|}{ Pre \& post } \\
\cline { 2 - 5 } & Mean \pm SD & Mean \pm SD & T & P-value \\
\hline $\begin{array}{l}\text { Cleaning of instruments immersion } \\
\text { method }\end{array}$ & $6.74 \pm 2.34$ & $13.07 \pm 1.65$ & 7.658 & $0.001^{* *}$ \\
\hline $\begin{array}{l}\text { Assemble cleaned items for } \\
\text { sterilization }\end{array}$ & $8.09 \pm 1.64$ & $17.70 \pm 1.78$ & 13.754 & $0.001^{* *}$ \\
\hline Manual cleaning method & $4.41 \pm 1.06$ & $7.15 \pm 1.05$ & 6.362 & $0.001^{* *}$ \\
\hline Mechanical cleaning & $3.87 \pm 1.45$ & $7.42 \pm 1.23$ & 6.468 & $0.001^{* *}$ \\
\hline Lubrication & $1.24 \pm 0.96$ & $2.37 \pm 0.87$ & 3.021 & $0.006^{*}$ \\
\hline $\begin{array}{l}\text { Glutaraldehyde disinfection } \\
\text { Total practices }\end{array}$ & $2.67 \pm 1.63$ & $5.89 \pm 0.93$ & 5.944 & $0.001^{* *}$ \\
\hline
\end{tabular}

Significant $<0.05 * \quad$ highly significant $\leq 0.001 * *$

As regard to the differences between mean scores of technicians' practices related to equipment sterilization pre and post implementation of educational interventions, Table 6 reveals that, there was highly statistically significant difference between mean scores of pre and post tests of technicians' practices as regards to preparation of instruments, sets, packs, and supplies for sterilization; loading sterilizer for sterilization; unloading sterilizer from sterilization; and cleaning of ultrasonic cleaner. Also there was highly statistically significant difference between mean scores of total technicians' practices pre and post implementations of educational interventions.

Table 6: Differences between mean scores of technicians' practices related to equipment sterilization pre and post implementation of educational interventions $(n=10)$

\begin{tabular}{|l|c|c|c|c|}
\cline { 2 - 5 } $\begin{array}{c}\text { Equipment sterilization process } \\
\text { based on technicians' } \\
\text { responsibilities }\end{array}$ & \multirow{2}{*}{ Pre } & \multirow{2}{*}{ Post } & \multicolumn{2}{|c|}{ Paired t-test } \\
\cline { 2 - 5 } & Mean \pm SD & Mean \pm SD & T & P-value \\
\hline $\begin{array}{l}\text { Preparation of instruments, sets, } \\
\text { packs, and supplies for sterilization }\end{array}$ & $18.75 \pm 2.35$ & $35.19 \pm 2.63$ & 14.740 & $0.001^{* *}$ \\
\hline Loading sterilizer for sterilization & $3.68 \pm 1.67$ & $8.64 \pm 1.08$ & 7.887 & $0.001^{* *}$ \\
\hline $\begin{array}{l}\text { Unloading sterilizer from } \\
\text { sterilization }\end{array}$ & $7.35 \pm 1.52$ & $15.37 \pm 1.17$ & 13.222 & $0.001^{* *}$ \\
\hline Cleaning of ultrasonic cleaner & $2.94 \pm 1.24$ & $5.87 \pm 0.93$ & 5.978 & $0.001^{* *}$ \\
\hline Total practices & $72.90 \pm 4.70$ & $82.60 \pm 4.50$ & 33.386 & $0.001^{* *}$ \\
\hline
\end{tabular}

Highly significant $\leq 0.001 * *$ 
Table 7 shows that, there is highly statistically significant difference between mean score of workers' total practices regarding ground, surfaces, and environmental cleaning pre and post implementation of the educational interventions.

Table 7: Differences between mean scores of workers' total practices regarding ground, surfaces, and environmental cleaning pre and post implementation of educational interventions $(\mathrm{n}=8)$

\begin{tabular}{|c|c|c|c|}
\hline \multirow{2}{*}{ Practice } & Workers' total practices & \multicolumn{2}{|c|}{ Paired t-test } \\
\cline { 2 - 3 } & Mean \pm SD & t & P-value \\
\hline Pre & $7.65 \pm 2.64$ & \multirow{2}{*}{10.249} & \multirow{2}{*}{$0.001^{* *}$} \\
\hline Post & $18.23 \pm 1.92$ & & \\
\hline
\end{tabular}

Highly significant $\leq 0.001 * *$

Table (8) shows that, there are statistically significance difference between nursing supervisors' opinions regarding services provided by central sterilization supply department pre and post implementation of the educational instructions.

Table 8: Percentage distribution of nurses' supervisors opinion regarding services provided by the central sterile supply department pre and post implementation of educational interventions $(\mathrm{n}=12)$

\begin{tabular}{|c|c|c|c|c|c|c|c|c|c|c|}
\hline \multirow[b]{2}{*}{ Items } & \multicolumn{4}{|c|}{ Pre } & \multicolumn{4}{|c|}{ Post } & \multicolumn{2}{|c|}{ Paired-t test } \\
\hline & Yes & $\%$ & No & $\%$ & Yes & $\%$ & No & $\%$ & $\mathbf{t}$ & P-value \\
\hline $\begin{array}{l}\text {-The sterile packs received from CSSD } \\
\text { are unusable. }\end{array}$ & 10 & 83.3 & 2 & 16.7 & - & - & 12 & 100 & 2.128 & $0.047 *$ \\
\hline $\begin{array}{l}\text {-The date of sterilization, expired date } \\
\text { and the responsible person are labeled } \\
\text { on the sterile pack. }\end{array}$ & 4 & 33.3 & 8 & 66.7 & 11 & 91.7 & 1 & 8.3 & 6.316 & $0.021 *$ \\
\hline $\begin{array}{l}\text {-The name of medical procedure is } \\
\text { labeled on the sterile pack. }\end{array}$ & 4 & 33.3 & 8 & 66.7 & 9 & 75 & 3 & 25.0 & 2.322 & $0.032 *$ \\
\hline $\begin{array}{l}\text {-Data on the sterile package compatible } \\
\text { with what is inside. }\end{array}$ & 9 & 75 & 3 & 25 & 12 & 100 & - & - & 2.072 & $0.048^{*}$ \\
\hline $\begin{array}{l}\text {-There is evidence on the sterile pack } \\
\text { that ensure sterilization process was } \\
\text { completed as required. }\end{array}$ & 2 & 16.7 & 10 & 83.3 & 12 & 100 & - & - & 2.064 & $0.010^{*}$ \\
\hline $\begin{array}{l}\text {-Every instrument within sterile pack is } \\
\text { used. }\end{array}$ & 2 & 16.7 & 10 & 83.3 & 10 & 83.3 & 2 & 16.7 & 1.809 & $0.047^{*}$ \\
\hline $\begin{array}{l}\text {-Each instrument within the sterile pack } \\
\text { is working and suitable for use. }\end{array}$ & 10 & 83.3 & 2 & 16.7 & 12 & 100 & - & - & 0.665 & $0.014 *$ \\
\hline $\begin{array}{l}\text {-There are brown or orange spots on the } \\
\text { surface of instruments. }\end{array}$ & 8 & 66.7 & 4 & 33.3 & 11 & 91.7 & 1 & 8.3 & 0.857 & $0.021 *$ \\
\hline $\begin{array}{l}\text {-Central sterilization department } \\
\text { provides the wards with requirements } \\
\text { such as surgical instruments, gowns, } \\
\text { linens, gauze, bandages and dressings. }\end{array}$ & 12 & 100 & - & - & 12 & 100 & - & - & 0.114 & $0.010 *$ \\
\hline
\end{tabular}

\section{Discussion}

Sterilization and disinfection in hospitals is an important issue for both the medical and the general community. There has been an increase in many infectious diseases such as Acquired Immunodeficiency Syndrome (AIDS) and Hepatitis B because of inadequate equipment sterilization. To minimize or prevent the risk of cross infection in the hospitals, specific recommendations have been issued by professional health agencies which should be practiced by doctors and health-care staff including nurses, theater assistants, lab technicians, and sanitation staff of hospitals. These recommendations include routine use of barrier techniques (gloves, masks, spectacles, etc.), heat sterilization of surgical instruments, and the universal precautions. This study was carried out to evaluate the effect of the educational interventions regarding sterilization process on quality of work delivered at the central sterile supply department [17].

Regarding nurses' knowledge about six components of equipment sterilization, the present study revealed that there was highly statistically significant difference between mean scores of total knowledge related 
to equipment sterilization pre and post implementation of educational interventions. The improvement in nurses' knowledge might be because the educational interventions were planned based on nurses identified learning needs during the preparatory phase. Moreover, due to clarity and comprehensive of educational interventions that was delivered and explained by the researcher to the studied subjects. This allows them to study well and understand the material explained to them. Improvement the knowledge of nurses working in CSSD will improve the quality of work; and reduce the incidence of infection related to inadequately sterilized equipments.

The results of the present study are in agreement with Jabbari, etal. (2012) [18] who stated that there are highly statistically significant difference between total score of nurses' knowledge pre and post implementation of training program in their study that titled "developing the use of quality indicators in sterilization practices". Also, Garbaccio and DeOliveira (2013) [19], stated that the level of knowledge of nurses related to equipment processing improved post implementation of training program compared with pre implementation of training program in their study that titled "hidden in the risk segment of decontamination: an assessment of the knowledge of professional and practices in a plastic surgery".

In relation to technicians' knowledge about six components of equipment sterilization, the present study showed that there was statistically significant differences between mean scores of technicians' total knowledge regarding equipment sterilization pre and post implementation of educational interventions. Enhancing technicians' knowledge may be due to that the content of the educational interventions were designed based on technicians' needs and the relevance of the content to their field of work, and may be because the educational interventions were designed according to technicians' responsibilities. Moreover, using different teaching methods by the researcher enable technicians to understand and acquire information about sterilization process six components.

Regarding technicians' knowledge, the findings of the present study are in agreement with Kulkarni and Chillarge (2015) [20] who stated that there are statistically significant difference between scores of technicians' knowledge pre and post implementation of training program in their study that titled "knowledge, attitude and practice regarding sterilization among staff in central sterile supply department of brims bidar: a hospital intervention study". They stated that CSSD requires knowledgeable and highly trained technicians, so that used surgical and other medical equipment can be safely reprocessed for reuse in other patients.

Concerning the workers' total knowledge related to six components of equipment sterilization, the present study reported that there is highly statistically significant difference between mean score of workers' total knowledge pre and post implementation of the educational interventions. This can be attributed to using simple, clear language that suit level of education of every staff. In addition, the frequent repetition of information by the researcher, revision of content at the beginning of each session and using different media such as booklet, posters and pictures. All previous issues lead to improving and updating knowledge of studied subjects (nurses, technicians and workers) regarding sterilization process components.

The results of the present study are in agreement with Abu salam, El-shezly and Abu Shady (2014) [21] who stated that the total score of knowledge among workers pre training program was low to moderate, as $70 \%$ of them had a low knowledge score and improved post implementation of training program, in their study that titled "an assistance system for guiding workers in central sterilization supply departments". Improving workers' knowledge helping in prevents failures of equipments during reprocessing and improves patients' safety.

Also, Drummond, Skidmore (2011) [22] reported that awareness among workers before intervention was unsatisfactory $(56.2 \%)$ related to methods of decontamination, disinfection and sterilization of equipment. A significant increase in awareness to $73.3 \%$ was observed after intervention. Results indicated that continuous in-service education is needed to improve, supplement and update knowledge in this field after basic training. In addition orientation programs for new workers should also be aimed at creating awareness and providing information on guidelines related to their duties and responsibilities.

As regard to nurses' practices related to six components of equipment sterilization, the present study showed that there was highly statistically significant difference between mean scores of total nurses' practices related to equipment sterilization process pre and post implementations of educational interventions. Improvement in the practices of nurses under study may be because the practical sessions of educational interventions were designed based on the responsibilities of nurses in the central sterile supply department, and using the role play and demonstrations methods during practical sessions.

The results of this study are in agreement with Kulkarni and Chillarge (2015) [20] who stated that knowledge and performance of nurses in relation to sterilization and disinfection process pre implementation of training program was inadequate, but it improved immediately post implementation of training program in their study that titled "knowledge, attitude and practice regarding sterilization among staff in central sterile supply department of brims bidar: a hospital intervention study". He reported that nurses did not believe that items should be rinsed in water after contact with glutaraldehyde and more than $25 \%$ thought that 10 min contact time provided sterilization. 
Also, Labrague, Arteche, Yboa and Pacolor, (2012) [23] stated that there was statistical significance difference association between knowledge on equipment sterilization and its application post implementation of training program. Thus nurses must continue to upgrade their knowledge to keep them abreast with the new trends in their study that titled "nurses' knowledge and practice related to equipment sterilization".

The present study revealed that there was highly statistically significant difference between mean scores of total technicians' practices regarding four components of equipment sterilization process pre and post implementations of educational interventions. This may be because the researcher allow hands-on for every staff members of the central sterile supply department to let them to practice by themselves, and showing them videos during practical sessions which motivate CSSDs' staff members.

This result is in agreement with Avachat, Zambare and Phalke (2012) [24] who stated that level of practice of technicians regarding processing of reusable medical instruments and equipment was inadequate, where small number of them done correctly. But common sterilization knowledge and procedures carried out increased after the training program implementation, in their study that titled "impact of training program on knowledge and awareness of equipment sterilization of a teaching hospital in India". He reported that is important to conduct in-service training to improve, supplement, and update knowledge and practice about sterilization and disinfection. There is a need to sensitize and motivate health-care staff through lectures and hands-on training through training program.

In addition, Bhandari and Bande (2016) [25] reported that highly significance difference was observed among technicians level of practice post implementation of training program in their study that titled "training program for improvement of knowledge, attitude, and practice of nursing staff and other paramedic staff regarding sterilization of instruments".

Concerning workers' practices, the present study revealed that there is highly statistically significant difference between mean score of workers' total practices regarding ground, surfaces, and environmental cleaning pre and post implementation of the educational interventions. The improvement in workers' total practice may be because the researcher was available in the CSSD during working hours of the staff, which allow her to observe workers during actual practice and clarify and correct any malpractice related to ground, surfaces, and environmental cleaning.

These results are supported by Quinn, Hansberger, Braun, Delclos and Huang (2015) [26] who stated that there was gaps in basic knowledge and practice of workers related environmental surface cleaning and disinfection, that was improved post educational program in their study that titled "cleaning and disinfecting environmental surfaces in CSSD: toward an integrated framework for infection and occupational illness prevention".

The present study revealed that there is statistically significance difference between nursing supervisors' opinions regarding services provided by central sterilization supply department pre and post implementation of the educational interventions. This may be because the CSSD staff is committing with the educational instructions received during practical and theoretical sessions and lead to improvement in the quality of services provided by CSSD post implementation of educational interventions. As shown in the present study the nursing supervisors reported that the date of sterilization and expired date and the responsible person are labeled on the sterile pack; the number and types of sterile items is labeled on the sterile pack; the name of medical procedure is labeled on the sterile pack; data on the sterile package compatible with what is inside; the sterile package contains sufficient and appropriate number of sterile instruments required for the procedure; each instrument within the sterile pack is working and suitable for use; and sterile instruments are delivered to the wards in time without delay. All previous activities are not done regularly and appropriately pre implementation of educational interventions, but improved post implementation.

These results are in agreement with Shriyan \& Shriyan (2015) [15] who stated that there are highly statistically significance difference in operating nurses' opinion regarding central sterilization supply department, where pre training program operating nurses reported that CSSD delay sterile material and supplies. The time schedule for processing of equipments after returned to CSSD was not conveyed of displayed in other areas of the hospital in their study that titled "a study on the efficiency of CSSD at a health care center". After observing this deficiency, it was recommended to display the time schedule at every operating theatre (OT) counter, intensive care unit (ICU), Wards and outpatients departments (OPD's). Accurate and real time scheduling assist in predicting staffing needs, ensuring availability of required equipment and supplies.

Also, Adisa, Fakeye and Aindero (2015) [27] reported that there is statistically significance difference between nurses' opinion pre and post implementation of training program and there is a need for periodic evaluation of nurse supervisors' opinion on CSSD practices at health facilities, to ensure identification of problem areas to focus on for future intervention.

It was stated that the quality of healthcare services mainly depends on practitioners' knowledge and technical skills: "the most important factors influence the quality of the work are knowledge, expertise, and 
commitment. Healthcare professionals should improve their competencies (i.e. the attitudes, knowledge, and skills) to deliver high-quality services "With updated knowledge benefits patients [20].

\section{Conclusion}

The results of this study concluded that implementation of the educational interventions has positive effect on improving the knowledge and practice of the central sterile supply department staff regarding sterilization process, as well as improving the satisfaction of nursing supervisors regarding the quality of work delivered by the central sterile supply department staff.

\section{Recommendations}

Periodic educational interventions and training should be conducted for central sterilization supply department staff (nurses, technicians and workers) in order to improve and keep them with updated knowledge and practice regarding to medical and surgical equipment sterilization.

\section{References}

[1]. A. Banu and G.T.Subhas, Central sterile supply department-need of the hour, J Pub Health Med Res, 1(2), 2013, 58-62.

[2]. C.Y. Hung and S.S. Lin, The process improvement of the supplies distribution of the central sterile services department, Journal of Microbiology, Immunology and Infection, 48 (2), 2015, 104.

[3]. Identifying Healthcare-associated Infections, 2015, CDC. Available from www.cdc.gov/ nhsn/PDFs/pscManual/2PSC_IdentifyingHAIs_NHSNcurrent.pdf acces. Accessed on 13/11/2016.

[4]. G. Kaushal, P. Doke, A. Shan and A. Mittal, Impact of training on knowledge, attitude and practices scores of ICU nurses regarding standard precautions of infection control in a super specialty hospital of Delhi, Paripex-Indian Journal of Research,4 (8), Aug 2015, 282-285

[5]. W. Rutala and D. Weber, Disinfection and sterilization in health care facilities: an overview and current issues, Infectious Disease Clinics of North America; 30 (3), 2016, 609-63.

[6]. L. Huber, Central sterile supply department professionals: a key piece in the OR quality puzzle, AORN Journal, 91(3), 2010, 319320 .

[7]. D.G. Hoyos, V. Wezel and V. Doornmalen, Case study on the orientation of phaco hand pieces during steam sterilization processes, Journal of Hospital Infection, 90(1), 2015, 52-58.

[8]. P.B. Batalden, F. Davidoff and R.K. Eesar, What is "quality improvement" and how can it transform healthcare?, Qual Saf Health Care, 16(1), Feb. 2007, 2-3.

[9]. B.T. Basavanthappa, Quality improvement; quality circle, nursing administration (London, Lippincott, 2009), second (ED.), pp. 732-735

[10]. C. Moss and M.M. Isley, Sterilization: a review and update, Obstetrics and Gynecology Clinics of North America, 42(4), 2015, 713-72.

[11]. P.A. Mews, Flash sterilization: a comprehensive view, Perioperative Nursing Clinics, 5(3), 2010, $291-326$

[12]. M.S. Favero and W.W. Bond, Reprocessing medical devices in health care settings, Disinfection, sterilization, and preservation, (Philadelphia, Lippincott Williams \& Wilkins, 2015), $5^{\text {th }}($ Ed), pp 881-917.

[13]. Standards Australia_organisation and Standards New Zealand. [AS/NZS]. (2014). Reprocessing of reusable medical devices in health service. Available at http://www.standards.org.au/ourorganisation/news/pages/clarification-on-AS-NZS-4187-and-AS-NZS4815.aspx. Accessed on 23/3/2016.

[14]. M. L. Young, Are you correctly using rigid sterilization containers for IUS, OR Manager, 30(3), 2014, 21-3.

[15]. A . Shriyan and A. Shriyan, A study on the efficiency of CSSD at a health care center, TJPRC: Journal of Nursing and Patient Safety \& Care (TJPRC: JNPSC), 1(2), Dec 2015, 7-16.

[16]. M. Kooshkebaghi, H. Ravaghi and N. Khalesi, Survey of the performance of the central sterile services department using hospital accreditation standards: a quantitative and qualitative study, International Journal of Review in Life Sciences., 5(11), 2015, 16-22.

[17]. A.G. Sukhlecha, S. Vaya , G.G Parmar, KD Chavda, Knowledge, attitude, and practice regarding sterilization among health-care staff in a tertiary hospital of western India, International Journal of Medical Science and Public health, 4(10), 2015,1-6.

[18]. H. Jabbari, H. Alikhah, N.S. Alamdari, M.N. Behzad, E. Mehrabi, L. Borzui, and F. Bakhshian, Developing the use of quality indicators in sterilization practices, Iran J Public Health; 41(7), 2012, 64-69.

[19]. J.L. Garbaccio, and A.C. de Oliveira, Hidden in the risk segment of decontamination: an assessment of the knowledge of professional and practices in a plastic surgery, Texto contexto-enferm; 22(4), 2013, 77-83.

[20]. S. Kulkarni, and C. Chillarge, Knowledge, attitude and practice regarding sterilization among staff in central sterile supply department of brims bidar: A Hospital Based Study, Indian Journal of Microbiology Research, 2 (3), 2015, $186-188$.

[21]. N. Abu Salam, A. El-Shazly and H. Abu Shady, Disinfection and sterilization awareness among healthcare providers in family health settings in Shebin Elkom, Menoufia, Egypt, Menoufia Medical Journal 27 (2014), 840-846.

[22]. D.C. Drummond and A.G. Skidmore, An evaluation of reusable instruments sterilization and disinfection in the workers, CMAJ. 15; 145 (8), 2011, 937-43.

[23]. L.J. Labrague, D.L. Arteche, B.C. Yboa, and N.F. Pacolor, Operating room nurses' knowledge and practice of disinfection and sterilization methods, J Nurse Care; 1(4), 2012, 69-77.

[24]. S. Avachat, M. Zambare and V. Phalke, Impact of sensitization workshop on knowledge and awareness of hospital-acquired infection among nurses of a teaching hospital in India, Public Health Short Communication S South East Asia Journal of Public Health; 2(2), 2012, 77-79.

[25]. S.R. Bhandari and R. Bande. Training program for improvement of knowledge, attitude and practice of nursing staff and other paramedical staff regarding sterilization of instruments, J Cont Med A Dent, (4 ) 2, May-August 2016, 55-63.

[26]. M.M Quinn, P.K. Henneberger, B. Braun, G.L. Delclos and V. Huang, Cleaning and disinfecting environmental surfaces in health care: toward an integrated framework for infection and occupational illness prevention, Am J Infect Control; 43(5), $2015,424-434$.

[27]. R. Adisa, T.O. Fakeye and V.O.Aindero, Evaluation of prescription pattern and patients' opinion on healthcare practices in selected primary healthcare facilities in Ibadan, South-Western Nigeria, Afr Health Sci., 15(4), Dec. $2015,1318-1329$. 